Original scientific paper

\title{
BUSINESS PROCESS MANAGEMENT MODEL AS AN APPROACH TO PROCESS ORIENTATION
}

\author{
Gudelj, M.*; Delic, M.**; Kuzmanovic, B. ${ }^{* *}$; Tesic, Z. ${ }^{* *} \&$ Tasic, N. ${ }^{* *}$ \\ *University of Split, Faculty of Electrical Engineering, Mechanical Engineering and Naval \\ Architecture, Split, Croatia \\ ** University of Novi Sad, Faculty of Technical Science, Novi Sad, Serbia \\ E-Mail: marko.gudelj@gmail.com,delic@uns.ac.rs, kbogdan@uns.ac.rs, ztesic@uns.ac.rs, \\ nemanja.tasic@uns.ac.rs
}

\begin{abstract}
Business process management (BPM) and process orientation is the focus of many researchers in the operational management. Various models have been developed that demonstrate the maturity, importance and role of BPM in setting a business strategy, as well as in design, implementation and control of business processes. Accepting the idea of the need for further research in this area, a research was conducted, and the results are presented in this article. The presented model is a result of numerous examples from various literary sources, experimentally obtained information, as well as knowledge from competent respondents. The model includes five dimensions of key factors for successful design, implementation and control of business processes, in accordance with the set of business strategies. Respondents in this research were middle and upper-level managers (315 respondents) from 45 organisations set in industrial, financial and telecommunications sectors. Research results show that organisations that have accepted the proposed model have a chance to take advantage of the process orientation positive effects and successfully manage business processes.

(Received in December 2020, accepted in April 2021. This paper was with the authors 1 month for 1 revision.)
\end{abstract}

Key Words: Business Process Management, Process Orientation, Operational Management, Model

\section{INTRODUCTION}

Business Process Orientation (BPO) or Process Orientation (PO) implies a focus on business processes instead of the classic hierarchical structure of the organisation [1]. Process orientation emphasizes processes opposed to hierarchy with a special focus on output and on meeting consumer requirements [2]. Having in mind the process flow (input, activity output), PO is often called a horizontal organisation, an organisation focused on business processes or simply a process organisation. Orientation to process organisation includes focus of managers and employees on business processes, business process mapping and process standardization, which significantly affects process performance and customer focused performance [3]. Empirical research has not sufficiently determined the impact of PO on increasing knowledge and maturity of its application in business organisations. Also, research has not clearly shown that the BPM approach affects the increase in acceptance of process orientation [4]. Many authors believe that there are challenges and limitations to the implementation of the principles of process orientation into an operational organisation. Total Quality Management (TQM), Process Improvement, and Business Process Reengineering (BPR) are some of the most commonly used approaches in increasing the appliance of business process orientation. The most important role is held by the Business Process Management approach, which managed to incorporate many positive aspects of previous approaches. BPM is viewed as a collection of management approaches based on software applications, which enable modelling, execution, monitoring, customer presentation of business processes and rules and which are based on the integration of functionalities of existing and new information systems [5].

The main idea in the BPM approach is to develop business processes while removing activities that do not add value and improving the flow of processes within various functions of 
the organisation [6]. BPM is an approach set to manage changes through business process improvement, encompassing the entire process life cycle, from analysis and design to implementation, automation and execution of business processes. Business process management is a broader concept than modelling and changing business processes because it enables the integration of business processes and information systems as well as the execution, coordination, monitoring and control of processes. Having in mind that the focus is on the organisation and business processes, the subject approach can be defined as achievement of organisational goals through improvement, management and control of essential (key) business processes [7]. BPM is more than business process improvement and reengineering, more than process design and more than software applications. It is an integral part of management that includes the implementation, execution and analysis of business processes. BPM is a field of knowledge that contains methods, techniques and tools for the design, execution, control and analysis of business processes [8].

The importance and role of BPM in the introduction of process orientation and successful business operations of the company has been discussed in many recent scientific papers, which influenced the decision to conduct this research. This research provides several important theoretical and managerial contributions that lead to better understanding of the essence of process orientation and business process management approaches. The basic dimensions of the BPM approach are set, and then the empirical research determines the importance of certain individual dimensions, their relationship and the impact on the maturity of BPM. Also, by setting such a BPM model, a contribution is made to the understanding of the role of business processes and process orientation by managers and employees, the significance of mapping processes, standardization and continuous process improvement. The result of this research is a small contribution to the ongoing effort to improve the efficiency of business processes and the effectiveness of industrial and service enterprises.

\section{THEORETICAL BACKGROUND AND RESEARCH QUESTIONS}

Basic goal of the concept of BPM is managing and improving business processes as organisations have accepted that process orientation can bring a certain degree of consistency and ensure acceptance of the company's strategic goals by employees [9]. BPM is not only a technology. BPM includes business processes, methodologies, metrics and IT technology used to design, monitor, measures and manage a business. BPM brings more capability than ever before to align operational activities with strategies and goals. This helps us to focus our enterprise resources on the creation and improvement of customer value. In this way, BPM is set in the centre of business processes as critical organisational asset that must be recognized and developed to deliver value-added products and services to customer.

Most authors that research problems of applying the process approach agree that the BPM approach allows organisations to implement strategies that were set, to design business processes, to implement business process models and to control business processes. When it comes to the choice of dimensions (key factors) for the successful implementation of BPM and PO, there are different opinions, but they do not differ much. Table I shows the dimensions of BPM approach that are highlighted by notable authors and which are the fundamental basis for the selection of the five dimensions that are key factors for successful design, implementation and control of business processes in accordance with the established strategies of business operations. 
Table I: Core dimensions of BPM identified in the literature.

\begin{tabular}{|c|c|c|}
\hline No. & Dimensions & Authors \\
\hline 1 & $\begin{array}{l}\text { Documented processes, Horizontal linkages across organisation structure, Availability of } \\
\text { systems and procedures to ensure consistency or performance, Implementation of tracking } \\
\text { and measurement of performance, Continuous improvement through problem solving, } \\
\text { Cultural change geared towards process orientation. }\end{array}$ & [10] \\
\hline 2 & $\begin{array}{l}\text { Strategic approach, Process management (methods), Information technology and standards, } \\
\text { Employee management, Business culture. }\end{array}$ & [11] \\
\hline 3 & $\begin{array}{l}\text { Processes awareness, Process description, Process measurement, Process control, Process } \\
\text { improvement, Resources and knowledge, Information technology. }\end{array}$ & [12] \\
\hline 4 & $\begin{array}{l}\text { Strategic alignment, Performance measurement, Organisational changes, IS support, } \\
\text { Employee training and empowerment. }\end{array}$ & [13] \\
\hline 5 & Goal-dimension, Process-dimension, Organisation-dimension, Environment-dimension. & [14] \\
\hline 6 & $\begin{array}{l}\text { Process design and documentation, Management commitment, process owner, Process } \\
\text { performance measurement, Corporate culture in line with the process approach, } \\
\text { Organisational structure in line with the process approach, People and expertise, Process- } \\
\text { oriented HR systems, Coordination and integration of process projects. }\end{array}$ & [15] \\
\hline 7 & Strategic Alignment, Governance, Methods, Information Technology, People, Culture & [16] \\
\hline 8 & $\begin{array}{l}\text { Manager commitment, Employee involvement, IT infrastructure, Strategic alignment, } \\
\text { Organisation culture, Organisation performance. }\end{array}$ & [17] \\
\hline 9 & $\begin{array}{l}\text { Information technology, Process management, Employee management, Strategy, Business } \\
\text { culture. }\end{array}$ & [18] \\
\hline 10 & $\begin{array}{l}\text { Investing in human capital, Support of top management, Structured and systematic } \\
\text { methodology, Align goals and targets to strategic planning, Continuous measurement and } \\
\text { monitoring, Control resistance to change control resistance to change, Clear and defined } \\
\text { responsibilities, Align IT (software) and BPM (relevant information), Controlling excessive } \\
\text { bureaucracy, and Executive support throughout the implementation stages. }\end{array}$ & [19] \\
\hline 11 & $\begin{array}{l}\text { Strategic perspective, Determination and documenting of processes, Measurement and } \\
\text { management of processes, Process-oriented organisational structure, HR management, } \\
\text { Process-oriented organisational culture, Market orientation, Suppliers' perspective } \\
\text { (business partners), Process-oriented information technology. }\end{array}$ & [20] \\
\hline 12 & $\begin{array}{l}\text { Organisation coordination, Process definition, Organisation structuring, Cultural fit, } \\
\text { Improvement, Measurement. }\end{array}$ & [21] \\
\hline
\end{tabular}

The research results are the basis for the selection of dimensions that represent key factors of BPM model in this study. The basis of the research presented in this paper is an adapted model, which is proposed by Ongena and Ravesteyn [12], as well as the model dimensions shown in Table I. The model is made out of five dimensions that are based on business process orientation and which can be a starting point for determining the significance, use and maturity of the BPM approach.

\subsection{Strategies and goals}

In order to achieve long-term success and improved performance, BPM must be closely related to the organisational strategy [22]. Understanding the strategic context of a BPM program is crucial in order to maximize the value of process improvement and close strategic relation between competitive strategy and operation functions [23]. The strategy of the organisation in the descriptive / organic approach is understood as planned or actual coordination of main goals and actions of the organisation, in time and space, which constantly connects the organisation with its environment. A mature organisation must be harmoniously connected horizontally and vertically. The goal and performance of a certain assignment must be consistent with the goals and performance of the process, and the goals and performance of the process must be consistent with the strategic goals and performance of the organisation [24]. The organisations strategy describes how the organisation intends to create sustainable value growth for its owners, consumers, and citizens. It is necessary to identify the critical processes in which the 
organisation has to be extraordinarily successful in order to achieve the objectives of the organisation concerning all relevant stakeholders and market segments. Failure to clarify the importance of implementing strategies and achieving goals is a crucial factor that can lead to failure in an organisations business [25]. Processes will not achieve business goals automatically; they require continuous and effective management - process-oriented management. Process support and contribute to the achievement of strategic, tactical and operational goals with the help of technology and people. It should be noted that the procedures of optimization and continuous improvement of business at the level of operational activities must be harmonized by mapping the value chains determined by the set strategies at the highest level of the organisation [26]. Strategies are becoming real through processes, and for that reason, the lack of connection between the company's strategy and its goals is considered one of the critical factors of high relevance [25].

\subsection{Process design}

The second dimension is process design. This dimension includes development of business process models through the organisation, which should contain detailed descriptions of processes (inputs, activities, outputs). Business process models should also define the organisational structure and employees who perform the processes, as well as technologies used in the implementation of the process, primarily information technology. The model shows which business processes are executed in the organisation and what are the interrelationships between them [27]. In order to successfully control, measure, analyse and improve business processes, it is necessary to define process goals and business process performance indicators while designing the model [12]. Business process design consists of creating a new specification of business processes, determining and displaying their activities and tasks, rules and definitions for exchanging information between functional groups, physical design and IT infrastructure. Using business process modelling, information is processed and displayed in process models [28]. Designing processes, among other techniques, contributes to determining the feasibility of projects to improve processes. This enables consolidation of knowledge, identification and formulation of changes, in accordance with future goals and needs of the current situation. This is why it is necessary to choose appropriate methods and techniques for the context of a real situation. Designed business process models can be applied to analyse how the process is currently running (As-Is), in order to support the design of what the process should be (To-Be) [29].

\subsection{Process measurement}

The most cited dimension was measurement and continuous monitoring. Ravesteyn and Batenburg [30] claim that BPM aims to continuously monitor processes to promote a steady improvement. Managing performance includes continuous observations, monitoring, tracking activities of the organisation and its processes and components, as well as the effects of these activities in order to gain insight into the amount and speed of progress made while achieving the goals that have been set. In doing so, it is necessary to measure performances and do performance evaluation, to compare planned with achieved, and to pass on the corresponding feedback information of achievements that were made [24].

Information obtained through measurement, analysis and evaluation is a necessary condition for sound decision-making for strategic management purposes. They enable monitoring (and anticipation) of changes significant for the purposes of performance management and describe whether and to what extent the organisation, process, program, project, business, achieve the set goals; enable demonstration of the achievements of set targets and goals, as well as description (and comparison) of progress towards set targets and goals. 
Performance measurement consists of a systematic definition and selection (quantitative or qualitative) of measurable indicators, as well as obtaining their measures at certain intervals, the tracking of which enables monitoring achievements and progress in the process of achieving previously set goals [24].

Measurement and analysis activities of the process include: setting measurement objectives, setting measures, determining procedures for data collection and storage, defining data analysis procedures, storing measurement data and analysis results.

\subsection{Process improvement and employee management}

Process improvement represents the stages in which customer requirements are accepted, requirements are realized, success is assessed and customer requirements are constantly checked in order to discover possible improvement activities. Process improvement represents interconnected phases; it is not a simple activity. As a result, it is a continuous improvement activity that must be done over time. It should not be an independent activity. In order to do so the organisation should focus on eliminating wastes and identifying new areas of improvement. The enablers within the model are the foundation that must be in place if continuous improvement is to be achieved or commenced in the first place. The enablers include: (a) the culture that promotes continuous improvement and innovation; (b) employee focus; (c) integration of continuous improvement; (d) focus on critical processes and standardization of best practices in a quality management system [31]. Progressive improvement involving everyone in the company. Improvement initiatives that increase successes and reduce failures. Identification and modelling of business processes and the use of information technology are not enough if there are no highly educated employees who can perform business processes. Employee management is a key lever for establishing process flows at an optimal level. Continuous education, training, empowerment, acquisition of knowledge and skills of employees affect the achievement and maintenance of the state of optimization [18]. The participation of the entire company, staff motivation and proper training policies for employees are just some human resource practices necessary to develop a continuous improvement program [32]. New employees must prepare for new jobs through the process of increase knowledge, training, encouraging innovation and creativity, improving morale and by applying an employee reward system [33]. Skrinjar and Trkman [4] point out as an important fact that it is important for BPM approach to ensure that employees are informed in real time about business results so that they can adjust their activities with strategies that ensure alignment of process orientation with company goals.

\subsection{Standardized processes and information technologies}

Standards in an organisation represent the documentation incurred in processes of developing, preparing, operating and supporting the production program and service processes. They include business process models that enable consistent performance of job activities across the organisation. When standardizing its business processes, the enterprise exploits the best practices throughout the company. Standardized business processes in an organisation provide a base for their improvement. Business process models show how they are currently executed and represent the basis for quality repetition of process execution in a future period. A standardized process includes the knowledge and experience of employees and thus provides a basis for educating and introducing new executors in the realization of the process, and at the same time forms the basis for innovating the process [34].

Business systems with standardized processes reduce the complexity of a process in a manner of elimination of redundant activities related to customers and suppliers, and 
elimination of non-value adding activities, in that way creating a basis for managing organisations performance [3].

The fifth dimension of the BPM model found in literature was an alignment between IT and the BPM approach. This dimension points to the fact that poor compliance between Information Technologies and BPM can result in failure to introduce a process organisation in the company. The need and provision of investment in IT is important because the great importance of IT in initiating and implementing changes identified in BPM projects [22,23]. Information technologies provide identical measurements, which contributes to the preparation of unified reviews and reports that managers need at the level of strategic decision-making, as well as in making decisions at the operational level [18].

All previous considerations are the basis for asking the following research questions (RQ):

RQ1: What is the general situation in organisations in the region in terms of understanding the impact of BPM approach on an organisation and management of business processes?

RQ2: The second goal of this paper is to investigate which key factors - dimensions in the BPM model influence its importance in managing an organisations business?

RQ3: Which dimensions have a greater impact on importance and maturity of the BPM model in business organisations?

\section{RESEARCH METHOD}

\subsection{Measures and questionnaire development}

To develop a questionnaire, BPM dimensions were operationalized, following the aforementioned literature sources (i.e. Table I). Measures build upon theoretical backbone and substantial confirmation in previous study results were considered to constitute dimensions of a research instrument. Face validity of the questionnaire was conducted with academics, scholars and practitioners, followed by the pilot test, in a small number of companies. Some minor corrections were made, however, there were no major complaints, regarding the instrument's length and clarity. Respondents' subjective estimates were collected with a fivepoint Likert scale [35].

\subsection{Sample demographic}

The sample structure consisted of medium and large organisations in the manufacturing industry, which have some organisational modality that deals with business process management in a certain way, the telecommunications, industry, and banks. The questionnaire surveyed over 300 respondents (from 45 organisations) whose composition by country is shown in Table II.

Table II : Respondent composition by the country they come from.

\begin{tabular}{|c|l|c|c|c|c|}
\cline { 3 - 6 } \multicolumn{2}{c|}{} & \multicolumn{3}{c|}{ Country } & \multirow{2}{*}{ Total } \\
\cline { 2 - 6 } \multicolumn{2}{c|}{} & Bosnia \& Herzegovina & Croatia & Serbia & \\
\hline \multirow{2}{*}{$\begin{array}{l}\text { Sector of } \\
\text { economy }\end{array}$} & Manufacturing sector & 39 & 58 & 48 & 145 \\
\cline { 2 - 7 } & Telecommunication sector & 16 & 16 & 14 & 46 \\
\cline { 2 - 7 } & Financial sector Total & 22 & 70 & 94 & 315 \\
\hline
\end{tabular}

\section{MODELLING RESULTS}

Due to its exploratory nature, this study was based on the variance-based method [35]. Although previously used in numerous studies, to the best of our knowledge, empirical validation of research constructs was rarely the case in the context of the research population. The lack of 
empirical evidence about constructs constitution provides strong motives to take exploratory route (variance-based), rather than confirmation approach (covariance-based). Also, the variance-based method (PLS-SEM) works better in the case of small sample sizes, where it is unreasonable to presume normality in the underlying data [35]. Thus, the exploratory route, under variance-based method (PLS-SEM) was taken, in favour of parameter estimation higher efficiency and greater statistical power [35]. The research model evaluation was carried out in two phases [35]. The measurement model was assessed first. The research model followed afterwards.

\subsection{The measurement model}

The construct constitution by its respectful manifest variables and reflective nature of research constructs was assessed under confirmatory factor analysis (CFA). According to literature recommendations, the analysis of following factors was conducted: construct reliability (Cronbach's $\alpha$ ), composite reliability $(C R)$, convergent $(C V)$, and discriminant validity $(D V)$ [35]. In favour of Cronbach's $\alpha$ and $C R$, the values were acceptable, yielding higher values than 0.7 . To conduct $C V$, average variance extracted $(A V E)$ and outer-loadings $(O L)$ were examined. $A V E$ was above the recommended value of 0.5 , while loadings were statistically significant $(t \geq 1.96)$, with bottom values of 0.7 , at least [35]. Further, discriminant validity was assessed under the Fornell-Larcker criterion [35]. Given that constructs have the strongest relations only with their indicators, and cross-loadings with other constructs have lower values, the discriminant validity was not an issue [35]. Finally, collinearity analysis has not shown values for variance inflation factor (VIF) greater than 4.3 [35]. These values are shown in Table III.

Table III: The measurement model statistics.

\begin{tabular}{|c|c|c|c|c|c|c|c|c|c|c|c|c|c|c|c|c|}
\hline No. & Con. & $I T$ & $O L$ & $\alpha$ & $C R$ & $\boldsymbol{A} \boldsymbol{V E}$ & 1 & 2 & 3 & 4 & 5 & 6 & 7 & 8 & 9 & 10 \\
\hline \multicolumn{17}{|c|}{ Core BPM Dimensions } \\
\hline 1 & $\mathbf{P M}$ & 7 & 0.83 & 0.93 & 0.94 & 0.70 & $\begin{array}{c}\mathbf{0 . 8 4} \\
F L \\
\end{array}$ & & & & & & & & & \\
\hline 2 & PD & 5 & 0.82 & 0.91 & 0.93 & 0.74 & 0.60 & $\begin{array}{c}\mathbf{0 . 8 6} \\
F L\end{array}$ & & & & & & & & \\
\hline 3 & PIEM & 8 & 0.71 & 0.93 & 0.94 & 0.68 & 0.80 & 0.65 & $\begin{array}{c}\mathbf{0 . 8 3} \\
F L\end{array}$ & & & & & & & \\
\hline 4 & SG & 4 & 0.79 & 0.82 & 0.88 & 0.64 & 061 & 0.48 & 0.58 & $\begin{array}{c}\mathbf{0 . 8 0} \\
F L\end{array}$ & & & & & & \\
\hline 5 & SPIT & 4 & 0.77 & 0.84 & 0.89 & 0.68 & 0.60 & 0.71 & 0.67 & 0.54 & $\begin{array}{c}\mathbf{0 . 8 2} \\
F L\end{array}$ & & & & & \\
\hline \multicolumn{17}{|c|}{ Core BPM Dimensions Relevance } \\
\hline 6 & $\mathbf{P M}$ & 7 & 0.73 & 0.91 & 0.93 & 0.66 & 0.62 & 0.40 & 0.51 & 0.44 & 0.34 & $\begin{array}{c}\mathbf{0 . 8 1} \\
F L\end{array}$ & & & & \\
\hline 7 & PD & 5 & 0.79 & 0.90 & 0.93 & 0.72 & 0.47 & 0.64 & 0.43 & 0.43 & 0.42 & 0.65 & $\begin{array}{c}\mathbf{0 . 8 5} \\
F L\end{array}$ & & & \\
\hline 8 & PIEM & 7 & 0.74 & 0.91 & 0.93 & 0.64 & 0.58 & 0.43 & 0.58 & 0.43 & 0.40 & 0.74 & 0.64 & $\begin{array}{c}\mathbf{0 . 8 0} \\
F L\end{array}$ & & \\
\hline 9 & SG & 3 & 0.81 & 0.77 & 0.87 & 0.68 & 0.41 & 0.36 & 0.41 & 0.52 & 0.30 & 0.61 & 0.64 & 0.59 & $\begin{array}{c}\mathbf{0 . 8 3} \\
F L\end{array}$ & \\
\hline 10 & SPIT & 3 & 0.82 & 0.81 & 0.89 & 0.73 & 0.20 & 0.33 & 0.34 & 0.28 & 0.52 & 0.40 & 0.52 & 0.41 & 0.44 & $\begin{array}{c}\mathbf{0 . 8 5} \\
F L\end{array}$ \\
\hline
\end{tabular}

Notes: $I T$ - Number of items per construct, $O L$ - Minimal value for outer-loadings per construct, $\alpha-$ Cronbach's alpha, $C R$-Composite reliability, $A V E$ - Average variance extracted, $F L$ - Fornell-Larcker criterion; Con. - Construct, PM - Process measurement, PD - Process design; PIEM - Process improvement and employee management; SG - Strategies and goals; SPIT - Standardized processes and information technologies. 


\subsection{Structural model results}

Path coefficients were tasted under the bootstrapping technique, with 5000 subsamples. Determination coefficients ( $R^{2}$ values) were found to be acceptable, speaking in favour of the research models predictive power [35]. Validated research model is shown in Fig. 1. Structural model results are described in Table IV.

Table IV: The structural model results.

\begin{tabular}{|c|c|c|c|c|c|c|c|c|}
\hline $\begin{array}{c}\text { Exogenous variable } \\
\text { (Core BPM } \\
\text { Dimensions) } \rightarrow\end{array}$ & $\begin{array}{c}\text { Endogenous } \\
\text { variable } \\
\text { (Relevance) }\end{array}$ & $R^{2}$ & $\boldsymbol{\beta}$ & $\mu$ & $\delta$ & $t$ & $p$ & Sig. \\
\hline Process measurement & \multirow{5}{*}{$\begin{array}{c}\text { Process } \\
\text { measurement }\end{array}$} & \multirow{5}{*}{0.396} & $0.539^{*}$ & $0.550^{*}$ & $0.143^{*}$ & $3.779^{*}$ & $0.000^{*}$ & Yes $^{*}$ \\
\hline Process design & & & 0.094 & 0.092 & 0.141 & 0.669 & 0.503 & No \\
\hline Proc. imp. and emp. man. & & & 0.044 & 0.037 & 0.122 & 0.363 & 0.717 & No \\
\hline Strategies and goals & & & 0.120 & 0.119 & 0.097 & 1.235 & 0.217 & No \\
\hline Stan. proc. and IT & & & -0.146 & -0.143 & 0.119 & 1.223 & 0.221 & No \\
\hline Process measurement & \multirow{5}{*}{ Process design } & \multirow{5}{*}{0.452} & 0.154 & 0.161 & 0.116 & 1.326 & 0.185 & No \\
\hline Process design & & & $0.644^{*}$ & $0.642^{*}$ & $0.087^{*}$ & $7.418^{*}$ & $0.000^{*}$ & $Y e s^{*}$ \\
\hline Proc. imp. and emp. man. & & & -0.108 & -0.115 & 0.113 & 0.958 & 0.338 & No \\
\hline Strategies and goals & & & $0.178^{* *}$ & $0.181^{* *}$ & $0.088^{* *}$ & $2.032^{* *}$ & $0.042^{* *}$ & $Y e s^{* *}$ \\
\hline Stan. proc. and IT & & & -0.154 & -0.152 & 0.104 & 1.486 & 0.137 & No \\
\hline Process measurement & \multirow{5}{*}{$\begin{array}{c}\text { Process } \\
\text { improvement } \\
\text { and employee } \\
\text { management }\end{array}$} & \multirow{5}{*}{0.377} & 0.268 & 0.273 & 0.144 & 1.865 & 0.062 & No \\
\hline Process design & & & 0.077 & 0.072 & 0.121 & 0.636 & 0.525 & No \\
\hline Proc. imp. and emp. man. & & & $0.310^{* *}$ & $0.312^{* *}$ & $0.135^{* *}$ & $2.287^{* *}$ & $0.022^{* *}$ & $Y_{e s}^{* *}$ \\
\hline Strategies and goals & & & 0.096 & 0.098 & 0.095 & 1.008 & 0.314 & No \\
\hline Stan. proc. and IT & & & -0.078 & -0.082 & 0.100 & 0.777 & 0.437 & No \\
\hline Process measurement & \multirow{5}{*}{$\begin{array}{l}\text { Strategies and } \\
\text { goals }\end{array}$} & \multirow{5}{*}{0.302} & 0.036 & 0.040 & 0.123 & 0.296 & 0.768 & No \\
\hline Process design & & & 0.169 & 0.160 & 0.129 & 1.314 & 0.189 & No \\
\hline Proc. imp. and emp. man. & & & 0.134 & 0.133 & 0.124 & 1.078 & 0.281 & No \\
\hline Strategies and goals & & & $0.428^{*}$ & $0.436^{*}$ & $0.103^{*}$ & $4.140^{*}$ & $0.000^{*}$ & Yes $^{*}$ \\
\hline Stan. proc. and IT & & & -0.168 & -0.165 & 0.112 & 1.493 & 0.136 & No \\
\hline Process measurement & \multirow{5}{*}{$\begin{array}{l}\text { Standardized } \\
\text { processes and } \\
\text { information } \\
\text { technologies }\end{array}$} & \multirow{5}{*}{0.315} & $-0.342^{* *}$ & $-0.341^{* *}$ & $0.133^{* *}$ & $2.577^{* *}$ & $0.010^{* *}$ & $Y_{e s}^{* *}$ \\
\hline Process design & & & -0.047 & -0.053 & 0.114 & 0.412 & 0.680 & No \\
\hline Proc. imp. and emp. man. & & & 0.213 & 0.213 & 0.129 & 1.652 & 0.099 & No \\
\hline Strategies and goals & & & 0.076 & 0.076 & 0.107 & 0.708 & 0.479 & No \\
\hline Stan.proc. and IT & & & $0.579^{*}$ & $0.587^{*}$ & $0.114^{*}$ & $5.095^{*}$ & $0.000^{*}$ & Yes ${ }^{*}$ \\
\hline
\end{tabular}

$*$ Statistical significance at $\alpha \leq 0.005 ; * *$ statistical significance at $\alpha \leq 0.05 ; \beta$ - path coefficient; $O$. - original sample; $\mu-$ sample mean; $\delta$-standard deviation; $t-t$ statistics (statistical significance at $t \geq 1.96$ ) 
CORE BPM

CORE BPM

DIMENSIONS

DIMENSIONS

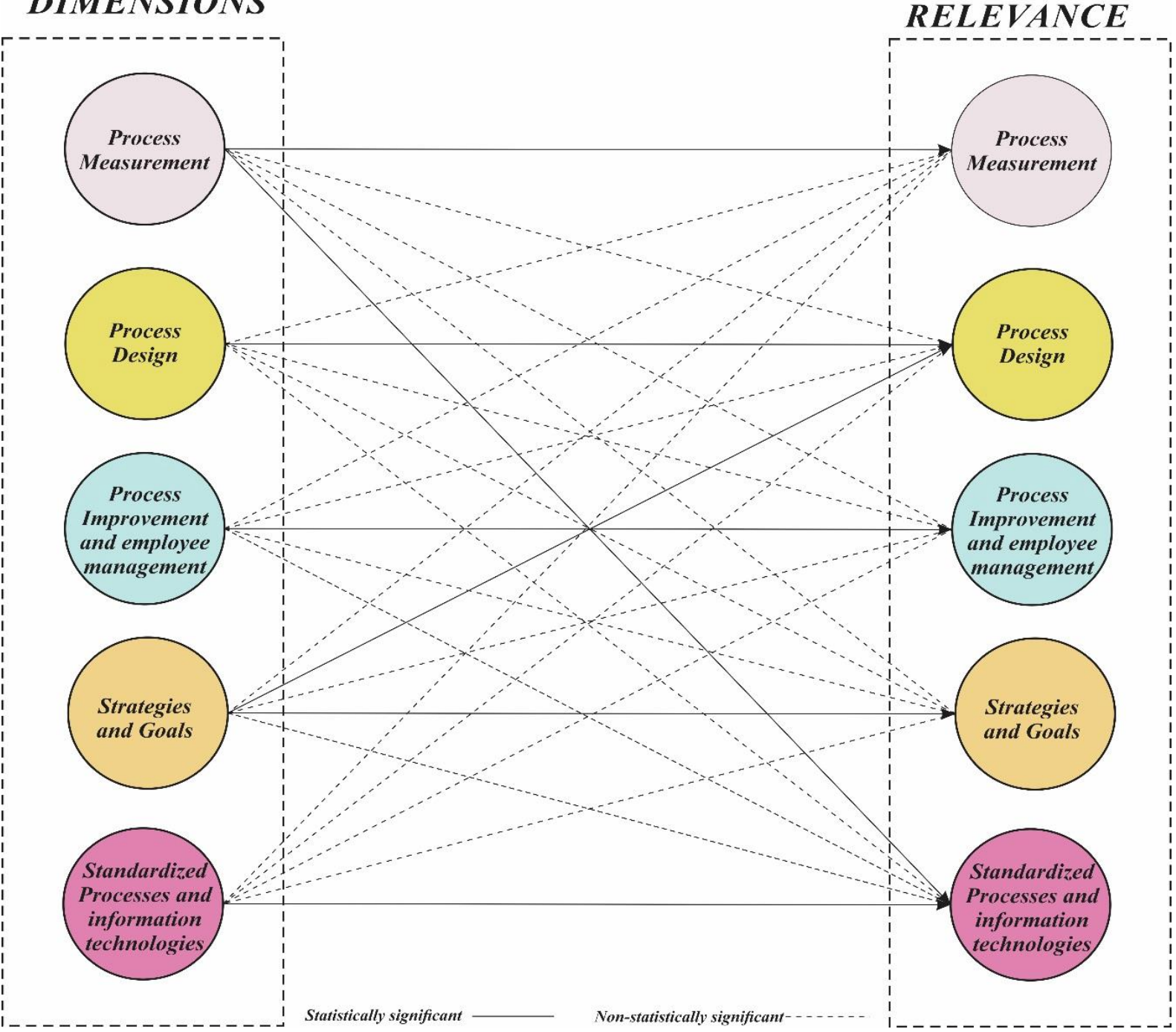

Figure 1: The structural model results.

\section{DISCUSSION}

The main result of the analysis of the data is the evidence that all dimensions identified in the literature were accepted as real critical factors according to the tacit knowledge of the experts. The research results shown in Table III show that all selected dimensions of the BPM model are significant in establishing process orientation and are key factors for successful design, implementation, control and adjustment of business processes in business strategies of companies.

The significance of these dimensions is as different as their interrelationships. Research has shown that strategies and goals is a quite important dimension, which is in line with many studies cited in this article. Strategies and goals are placed at the centre of the model designed by Kaplan and Norton [26]. Strategy planning, strategy implementation, strategic performance management system design are the macro-level factors impacting the BPM effectiveness in measuring and managing business processes. A strategy-driven process improvement plan captures the organisations overall approach towards BPM. The process improvement plan should be directly derived from the organisations strategy, and should outline how process improvement initiatives are going to meet strategically prioritized goals [16]. 
Standardized processes and information technologies is the second most important dimension, which shows that managers are aware of the need to apply information technology as a tool for successful business process management. The need for standardization of business processes is specifically considered in the LEAN concept of business improvement as a key factor for repeating the success in the execution of processes and their continuous improvement. Information technology has a great influence on communication, process execution and acquisition of knowledge from employees, but at the same time employees must have the necessary knowledge and skills to use complex information systems [22].

Employee management and process improvement is also a very important dimension, which ensures that the organisation has human resources that have the appropriate knowledge, skills, experience and ability to manage processes under the set strategies and continuously improve business processes. Knowledge, training and empowerment of employees are increasingly considered as an important prerequisite for the success of BPM [16]. All employees must know what their role is in the process, how their work affects others and how they contribute to achieving organisational goals. Further, they should understand how individual processes contribute to the overall goals of the organisation. Therefore, strategies and goals must be understood by all employees from top management to workers on production lines [4]. The structural model results show that Process measurement is also a significant dimension of BPM. Successful process measurement enables reviewing achieved results as well as it creates the basis for adjusting business processes. Through the measurement of the process, employees are constantly informed about the results in terms of achieving the set goals. This makes it easier for employees to adjust their behaviour to achieve goals [4].

\section{CONCLUSION}

The business Process Management approach is a collection of methods and tools that allow us to answer the questions: what our processes are, how do we design processes, how do we ensure their performance, how do we manage processes and how technologies and human resources should support processes. The importance of BPM for the organisation is the reason for conducting the research presented in this paper. The choice of dimensions as key factors was made based on knowledge collected from theoretical and empirical research of many authors. The identified and analysed dimensions can be considered as a starting point for organisations and managers who want to successfully implement BPM. Organisations that focus on analysis and control of the dimensions identified in this paper will have greater chances of success in implementing the BPM approach [19].

The results of the research show that in most companies in countries that make up the sample of the survey, the situation is positive in terms of understanding the impact of the BPM approach to the organisation and management of business processes. The selected dimensions of the BPM model were recognized by the surveyed participants and it is shown which dimensions have a greater impact on business process management and which dimensions are more important for the success of process orientation. Also, the results of the research show that other authors agree with the research, especially in terms of giving a certain advantage to the role of human resources over technology. The research is in concurrence with other authors who support the idea that knowledge, skills, experience and responsibility of human resources are crucial for creating intelligent business systems or businesses for the future.

Results of this research lead to the conclusion that company managers in surveyed countries although aware of the importance of process orientation and dominance of the BPM approach, give advantage to technology over the role of human resources, which is a certain, not big, limitation. Future research should focus on determining the importance of business process models in implementing business process performance management systems. 


\section{ACKNOWLEDGEMENT}

The results presented in this paper are part of the research within the project "Research of the possibility of applying artificial intelligence in industrial engineering, management and teaching process at DIIM", at the Department of Industrial Engineering and Management, Faculty of Technical Sciences in Novi Sad, University of Novi Sad, Republic of Serbia.

\section{REFERENCES}

[1] Reijers, H. A. (2006). Implementing BPM systems: the role of process orientation, Business Process Management Journal, Vol. 12, No. 4, 389-409, doi:10.1108/14637150610678041

[2] McCormack, K. P.; Johnson, W. C. (2001). Business Process Orientation: Gathering the EBusiness Competitive Advantage, St. Lucie Press, Boca Raton

[3] Van Assen, M. (2018). Process orientation and the impact on operational performance and customer-focused performance, Business Process Management Journal, Vol. 24, No. 2, 446-458, doi:10.1108/BPMJ-10-2016-0217

[4] Škrinjar, R.; Trkman, P. (2013). Increasing process orientation with business process management: Critical practices', International Journal of Information Management, Vol. 33, No. 1, 48-60, doi:10.1016/j.ijinfomgt.2012.05.011

[5] Ravesteyn, P.; Versendaal, J. (2007). Success factors of business process management systems implementation, Proceedings of the $18^{\text {th }}$ Australasian Conference on Information Systems, 396406

[6] Kujansivu, P.; Lonnqvist, A. (2008). Business process management as a tool for intellectual capital management, Knowledge and Process Management, Vol. 15, No. 3, 159-169, doi: $10.1002 / \mathrm{kpm} .307$

[7] Jeston, J.; Nelis, J. (2006). Business Process Management: Practical Guidelines to Successful Implementations, $1^{\text {st }}$ edition, Butterworth-Heinemann, Oxford

[8] Lindsay, A.; Downs, D.; Lunn, K. (2003). Business processes-attempts to find a definition, Information and Software Technology, Vol. 45, No. 15, 1015-1019, doi:10.1016/S09505849(03)00129-0

[9] Nadarajh, D.; Kadir, S. L. S. A. (2016). Measuring business process management using business process orientation and process improvement initiatives, Business Process Management Journal, Vol. 22, No. 6, 1069-1078, doi:10.1108/BPMJ-01-2014-0001

[10] Goldkuhl, G.; Lind, M. (2008). Coordination and transformation in business processes: towards an integrated view, Business Process Management Journal, Vol. 14, No. 6, 761-777, doi:10.1108/ 14637150810915964

[11] DeBruin, T. (2007). Insights into the evolution of BPM in organizations, Proceedings of the $18^{\text {th }}$ Australasian Conference, 632-642

[12] Ongena, G.; Ravesteyn, P. (2020). Business process management maturity and performance: A multi group analysis of sectors and organization sizes, Business Process Management Journal, Vol. 26, No. 1, 132-149, doi:10.1108/BPMJ-08-2018-0224

[13] Hammer, M.; Champy, J. (1993). Reengineering the Corporation: A Manifesto for Business Revolution, $1^{\text {st }}$ edition, Harper Business, New York

[14] Vom Brocke, J.; Zelt, S.; Schmiedel, T. (2016). On the role of context in business process management, International Journal of Information Management, Vol. 36, No. 3, 486-495, doi:10.1016/j.ijinfomgt.2015.10.002

[15] Kohlbacker, M.; Gruenwald, S. (2011). Process orientation: conceptualization and measurement, Business Process Management Journal, Vol. 17, No. 2, 267-283, doi:10.1108/ 14637151111122347

[16] Rosemann, M.; vom Brocke, J. (2015). The six core elements of business process management, vom Brocke, J.; Rosemann, M. (Eds.), Handbook of Business Process Management, Springer, Berlin, 107-122, doi:10.1007/978-3-642-45100-3_5

[17] Wong, W. P.; Tseng, M.-L.; Tan, K. H. (2014). A business process management capabilities perspective on organisation performance, Total Quality Management \& Business Excellence, Vol. 25, No. 5-6, 602-617, doi: $10.1080 / 14783363.2013 .850812$ 
[18] Anđelković-Pešić, M.; Janković-Milić, V.; Anđelković, A. (2012). Business process management maturity model: Serbian enterprises' maturity level, Ekonomika preduzeća, Vol. 60, No. 3-4, 190198, doi:10.5937/ekopre1204190A

[19] Do Amaral Castro, B. K.; Dresch, A.; Veit, D. R. (2020). Key critical success factors of BPM implementation: a theoretical and practical view, Business Process Management Journal, Vol. 26, No. 1, 239-256, doi:10.1108/BPMJ-09-2018-0272

[20] Novak, R.; Janeš, A. (2019). Business process orientation in the Slovenian power supply, Business Process Management Journal, Vol. 25, No. 4, 780-798, doi:10.1108/BPMJ-05-2017-0130

[21] Armistead, C.; Machin, S. (1997). Implications of business process management for operations management, International Journal of Operations \& Production Management, Vol. 17, No. 9, 886898, doi: $10.1108 / 01443579710171217$

[22] Trkman, P. (2010). The critical success factors of business process management, International Journal of Information Management, Vol. 30, No. 2, 125-134, doi:10.1016/ j.ijinfomgt.2009.07.003

[23] Hung, R. Y.-Y. (2006). Business process management as competitive advantage: a review and empirical study, Total Quality Management \& Business Excellence, Vol. 17, No. 1, 21-40, doi:10.1080/14783360500249836

[24] Balaban, N.; Ristić, Ž. (2012). Upravljanje performansom, M\&I Systems, Co. Group, Novi Sad (in Serbian)

[25] Rummler, G. A.; Brache, A. P. (1995). Improving Performance: How to Manage the White Space on the Organization Chart, $2^{\text {nd }}$ edition, Jossey-Bass, San Francisco

[26] Kaplan, R. S.; Norton, D. P. (2004). Strategy Maps: Converting Intangible Assets into Tangible Outcomes, Harvard Business School Press, Boston

[27] Kohlbacher, M.; Reijers, H. A. (2013). The effects of process-oriented organizational design on firm performance, Business Process Management Journal, Vol. 19, No. 2, 245-262, doi:10.1108/14637151311308303

[28] Eikebrokk, T. R.; Iden, J.; Olsen, D. H.; Opdahl, A. L. (2011). Understanding the determinants of business process modelling in organizations, Business Process Management Journal, Vol. 17, No. 4, 639-662, doi:10.1108/14637151111149465

[29] Harmon, P. (2007). Business Process Change: A Guide for Business Managers and BPM and Six Sigma Professionals, $2^{\text {nd }}$ edition, Morgan Kaufman Publisher, Burlington

[30] Ravesteyn, P.; Batenburg, R. (2010). Surveying the critical success factors of BPM-systems implementation, Business Process Management Journal, Vol. 16, No. 3, 492-507, doi:10.1108/14637151011049467

[31] Kaye, M.; Anderson, R. (1999). Continuous improvement: the ten essential criteria, International Journal of Quality \& Reliability Management, Vol. 16, No. 5, 485-509, doi: $10.1108 / 02656719910249801$

[32] Rapp, C.; Eklund, J. (2007). Sustainable development of a suggestion system: Factors influencing improvement activities in a confectionary company, Human Factors and Ergonomics in Manufacturing \& Service Industries, Vol. 17, No. 1, 79-94, doi:10.1002/hfm.20064

[33] Dijkman, R.;Vanderfeesten, I.; Reijers, H. A. (2016). Business process architectures: overview, comparison and framework, Enterprise Information Systems, Vol. 12, No. 2, 129-158, doi: $10.1080 / 17517575.2014 .928951$

[34] Nunnally, J. C.; Bernstein, I. H. (1994). Psychometric Theory, McGraw-Hill, New York

[35] Hair, J. F. J.; Hult, G. T. M.; Ringle, C. M.; Sarstedt, M. (2013). A Primer on Partial Least Squares Structural Equation Modeling (PLS-SEM), Sage Publications, Thousand Oaks 